\title{
Synchronous Reluctance Motor Iron Losses: Analytical Model and Optimization
}

\author{
Hanafy Mahmoud, Michele Degano, Giacomo Bacco, Nicola Bianchi, and Chris Gerada
}

\begin{abstract}
The complex rotor structure of synchronous reluctance machines causes a high harmonic content in the air-gap flux density and then flux density fluctuations in different iron parts. The importance of determining accurately the total iron losses in the whole motor structure is crucial even during the first design stage. An analytical model is presented to predict the total iron losses as well as the average torque and ripple. Then, an optimization approach is applied to such a model to improve the motor performance. In addition, in several applications a field weakening is required to extend the speed range of the motors. Therefore, it is important to design and optimize the machine not only considering the base speed working point, but also the field weakening operation. An optimization process is applied to two different operating conditions, simultaneously, applying the fast analytical synthesis. The validation of the model accuracy is assessed by means of finite element analysis.

Index Terms-Synchronous reluctance machine, Analytical analysis, Optimization approach, Finite element analysis.
\end{abstract}

\section{INTRODUCTION}

Undoubtedly, the electric motors have the lion's share of electric energy consumption [1]-[3]. Thus, during the recent years, there is a growing interest in high efficiency electrical motors. For this reason, the motor designers are looking for minimizing the resistive losses (winding losses), the mechanical losses (friction losses), and the electromagnetic losses (iron losses). The winding losses can be reduced by using concentrated winding arrangement, besides, energy efficient ball bearings or magnetic bearings are used to reduce the friction losses. Furthermore, the iron losses can be minimized by selecting the proper material, manufacturing process, and geometry of the motor [4], [5].

Synchronous reluctance (SynRel) machines have been recently recognized to be very good candidates for several applications requiring a wide speed range. Their main advantages are: higher efficiency with respect to the induction machines, fault tolerant capability, wide field weakening (FW) range and absence of costly permanent magnets.

Fig. 1 shows the polar diagram of a SynRel machine representing the maximum torque per ampere (MTPA) and the FW trajectories according to the current and voltage limits. From the rated operating condition (point $\mathrm{B}$ ), to operate the machine at higher speed, the current angle is increased maintaining a constant current amplitude reaching point $B^{\prime}$, where the maximum torque per voltage (MTPV) trajectory starts. Then, the $d$-axis current is reduced. During the FW operations, the main flux of the machine is reduced, thus, the flux density variations in the different motor iron parts are reduced [5].

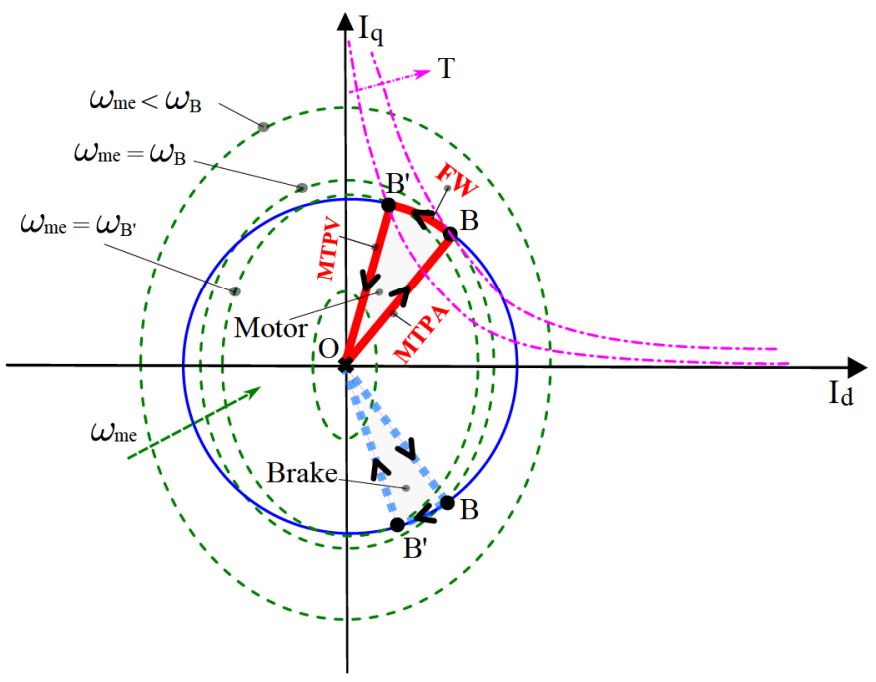

Fig. 1: Operating limits and working points of a SynRel motor.

However, the impact of the rotor anisotropy on the air-gap flux density distribution increases: the major part of the flux crosses the flux-barriers, i.e., in the $q$-axis direction. Hence, the harmonic content in the air-gap flux density waveform is increased. In addition, the speed/frequency is augmented. Consequently, the eddy current losses become the dominant iron losses component at the FW operating condition.

At the MTPA operating condition (point B in Fig. 1) the flux density variation in the iron is much lower than that at FW operating conditions. Besides, the frequency is lower, and hence, the eddy current losses are lower comparing to those of the FW operating conditions. However, the fundamental components of the flux density variations, in both stator teeth and yoke, have a considerable value. Therefore, the hysteresis losses of these fundamental components are computed, while the losses produced by higher harmonic components can be neglected, due to their minor hysteresis loops.

In the literature, there is no generic, rapid, and accurate analytical model to compute the iron losses in both rotor and stator iron parts of the SynRel motors. Most of previous models are based on a finite element (FE) analysis to obtain the flux density variations in the motor iron parts and derive the iron losses [6]-[10]. The results are accurate and validated by experimental results, but they refer to a particular motor geometry so that they lose generality.

In [11], an analytical approach is proposed to compute the 
flux density fluctuation in the stator teeth. However, this model is based on the hypothesis of a short-circuit condition. Furthermore, the analytical model presented in [12] computes the flux density variation in different motor iron parts. Nevertheless, this model is based on some assumptions: the flux-barrier ends are equally spaced and the stator MMF is sinusoidally distributed.

In [5], an analytical model evaluating the air-gap flux density for a generic stator and rotor geometry is presented. It considers all stator MMF harmonics, computes the flux density variations in the stator teeth, focuses on the computation of the stator teeth eddy current losses at the FW operating conditions. Then, an optimization approach is used to minimize these losses. However, that work did not consider: (a) the computations of the overall iron losses in the stator teeth and yoke (hysteresis and eddy current), (b) the rotor iron losses, which might be considerable for a solid rotor structure commonly used for high speed application, (c) the other magnetic performance parameters, as the torque ripple and the average torque in the optimization approach, (d) the motor non-linearity at the different operating conditions, which are the stator slotting effect and the magnetic saturation effect of both rotor and stator iron.

To fill this gap, the aims of this paper (Part I) are:

1) to extend the analytical model proposed in [5] to compute the total iron losses of the SynRel motor for all the operating conditions (MTPA, FW and MTPV);

2) to implement different optimization approaches not only for minimizing the total iron losses but also for minimizing the torque oscillations as well as maximizing the average torque. These optimizations are carried out at different operating conditions at the same time (Point B and $\mathrm{B}^{\prime}$ in Fig. 1, as an example).

The paper is organized as follows: Section II briefly describes the analytical model. Section III discusses the computations of the iron losses in the different iron parts of both stator and rotor. Section $\mathrm{V}$ shows an optimization of the rotor geometry to minimize the total iron losses and the torque ripple, as well as, to maximize the average torque for two different operating points ( $\mathrm{B}$ and $\mathrm{B}$ '), simultaneously. The optimization approach is carried out on the analytical model and is confirmed by the FE analysis. The motor non-linear behaviour, such as the iron saturation and the stator slotting effect has considered by the extended analytical model in [13].

As an example, a 36 slots, four-pole reluctance machine is analyzed, considering three flux-barriers per rotor pole $\left(N_{b}=3\right)$, as shown in Fig. 2. The analytical model is applied at both operating points (B and B'), shown in Fig. 1. The current density is the same for both operating conditions $\left(J=3 \mathrm{~A} / \mathrm{mm}^{2}\right)$ and the current vector angles are $45^{\circ}$ and $80^{\circ}$, respectively.

\section{ANALYTICAL MODEL}

Fig. 2 shows a sketch of one rotor pole. The corresponding magnetic network is described in [14], [15]. From such a

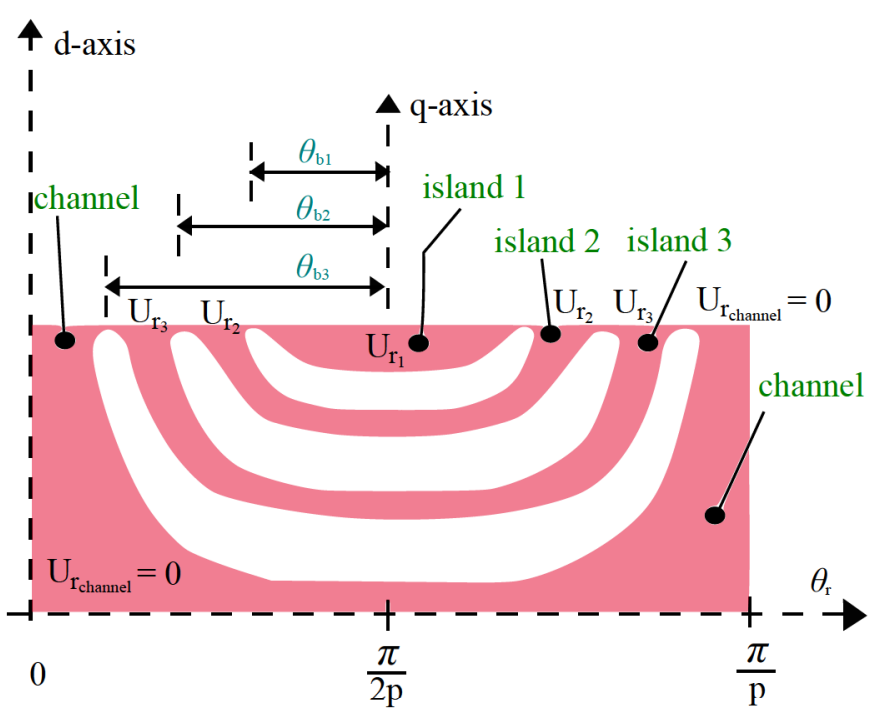

Fig. 2: Planar geometry of a rotor pole.

magnetic network, the scalar magnetic potential of the $i$-th rotor island (labelled $U_{r_{i}}$ ) is computed as

$$
U_{r_{i}}=U_{r_{i+1}}+\frac{D t_{b_{i}}}{2 l_{b_{i}}} \int_{\frac{\pi}{2 p}-\vartheta_{b_{i}}+\vartheta_{m}}^{\frac{\pi}{2 p}+\vartheta_{b_{i}}+\vartheta_{m}} \frac{U_{s}-U_{r_{i}}}{g} \mathrm{~d} \vartheta_{\mathrm{s}}
$$

where $i=1,2,3$ and $U_{r_{i+1}}=0$, if $i+1>N_{b}$. Then, $g$ is the air-gap length, $\vartheta_{b_{i}}$ is the end angle of the $i$-th flux-barrier, $\vartheta_{m}$ refers to the rotor position, and $\vartheta_{s}$ is the angular coordinate in the stator stationary reference frame. All the aforementioned angles are expressed in mechanical degrees. $t_{b_{i}} / l_{b_{i}}$ is the ratio between thickness and length of the $i$-th flux barrier, $D$ is the inner stator diameter. Finally, $U_{s}$ is the stator scalar magnetic potential, given by

$$
U_{s}\left(\vartheta_{s}\right)=\frac{-D}{2} \sum_{v} \hat{K}_{v} \cos \left(v p \vartheta s-p \vartheta_{m}-\alpha_{i}^{e}\right)
$$

where $p$ is the number of pole pairs, $\hat{K}_{v}$ is the peak of the $v$-th harmonic of the electric loading (Its expression is reported in [15]) and $\alpha_{i}^{e}$ is the current vector angle in electrical degrees).

When the scalar magnetic potential distributions of the stator and rotor are computed, the air-gap flux density distribution is derived as

$$
B_{g}\left(\vartheta_{s}, \vartheta_{m}\right)=\mu_{\circ} \frac{-U_{s}\left(\vartheta_{s}, \vartheta_{m}\right)+U_{r}\left(\vartheta_{s}, \vartheta_{m}\right)}{g}
$$

where the positive direction for $\mathrm{Bg}$ is from rotor to stator and $\mu_{\circ}$ is the free space permeability.

Finally, the electromagnetic torque is expressed as

$$
\tau_{m}\left(\vartheta_{m}\right)=\frac{-\mu_{\circ} D^{2} L_{s t k}}{4} \int_{0}^{2 \pi} \frac{B_{g}\left(\vartheta_{s}, \vartheta_{m}\right) K_{s}\left(\vartheta_{s}, \vartheta_{m}\right)}{g} d \theta_{s}
$$

where $K_{s}\left(\vartheta_{s}\right)$ is the electric loading [15]. Thus, the torque 
ripple is easily determined by

$$
\% \tau_{\text {ripple }}=\frac{\max \left[\tau_{m}(t)\right]-\min \left[\tau_{m}(t)\right]}{\tau_{\text {avg }}} \cdot 100 \%
$$

where $\tau_{a v g}$ is the average torque.

\section{IRON FluX DEnsity VARIATIONS COMPUTATIONS}

The linear analytical model presented in the last section allows to estimate the air-gap flux density distribution, the torque ripple and the average torque. Once the air-gap flux density $B_{g}\left(\vartheta_{s}\right)$ is computed at different rotor positions, the flux density variations in the different motor iron parts can be computed, and hence, the iron losses can be accurately estimated. The following subsections A, B and C deal with the calculation of the flux density variations in the stator tooth and back-iron as well as in the rotor iron islands. As an example, a SynRel motor with the geometrical data reported in [15], [16] is considered.

\section{A. Stator iron parts}

The flux density variation in the $n$-th stator tooth is computed as

$$
B_{t_{n}}\left(\vartheta_{m}\right)=\frac{D}{2 w_{t}} \int_{\gamma_{s}+(n-1) \alpha_{s l o t}}^{\gamma_{s}+n \alpha_{s l o t}} B_{g}\left(\vartheta_{s}, \vartheta_{m}\right) \mathrm{d} \vartheta_{\mathrm{s}}
$$

where $\gamma_{s}$ identifies the position of the magnetic axis of phase $a$, which acts as the reference of $\vartheta_{\mathrm{s}}$ with respect to the first slot, $w_{t}$ is the tooth width, $\alpha_{s l o t}$ is the slot angle and it is equal to $2 \pi / Q_{s}$, where $Q_{s}$ is the number of stator slots.

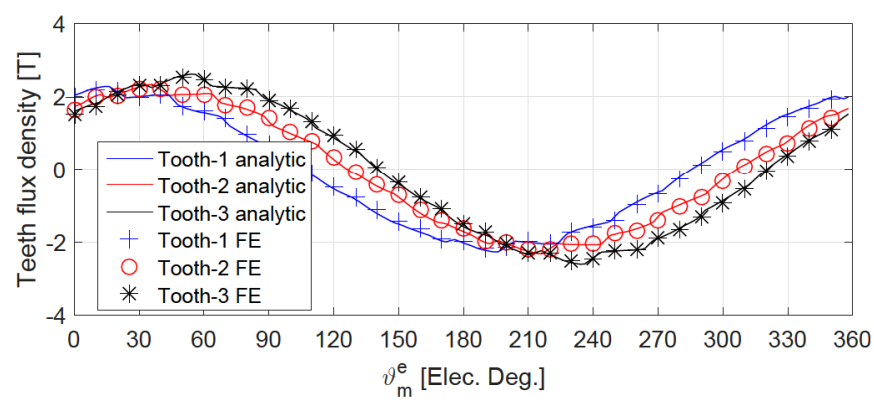

Fig. 3: Flux density variation in the first, second, and third stator tooth, computed from the analytical and FE models at the operating point $\mathrm{B}$.

Fig. 3 shows a good agreement between analytical (solid lines) and FE (symbols) models. It can be demonstrated that the tooth flux density assumes $q$ different behaviours, where $q$ is the number of slots per pole and per phase. The analytical model is applied for rotor positions spanning from $0^{\circ}$ to $q p \alpha_{\text {slot }}$ (electrical degrees) instead of $360^{\circ}$ (electrical degrees). The flux density of the stator teeth can be predicted for a complete electrical period computing its variation only for $Q_{s} / p$ teeth. As a consequence, the model computational time is reduced by almost $84 \%$.

To estimate the actual flux in the stator yoke, its part corresponding to a pole pair is split into $Q_{s} / p$ sections, each

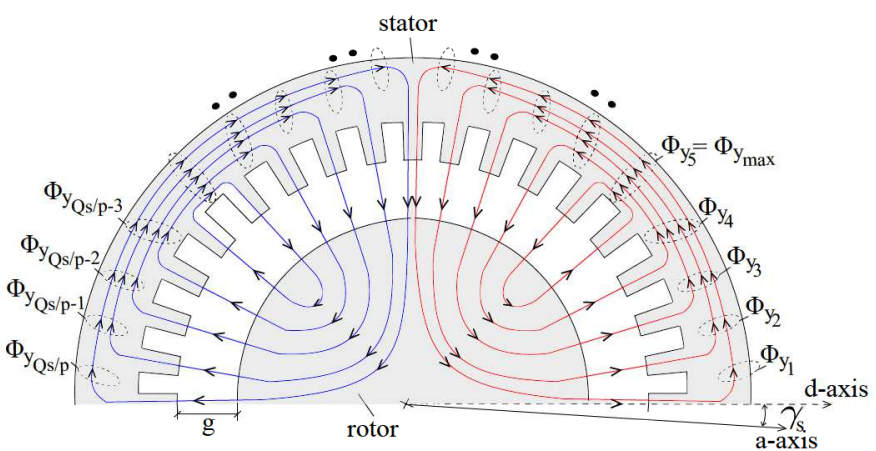

Fig. 4: Flux lines in the stator teeth and back iron.

one covering a slot angle, as shown in Fig. 4. The virtual flux flowing through a generic $s$-th section is given by

$$
\tilde{\phi}_{y_{s}}\left(\vartheta_{m}\right)=w_{t} L_{s t k} \sum_{n=1}^{n=s} B_{t_{n}}\left(\vartheta_{m}\right)
$$

where $L_{s t k}$ is the stack length of the motor. Then, the actual flux in the yoke is achieved by removing the average value from (7), so that it can expressed, independent of the rotor position or the operating condition, as follows

$$
\phi_{y_{s}}\left(\vartheta_{m}\right)=\tilde{\phi}_{y_{s}}\left(\vartheta_{m}\right)-\frac{1}{Q_{s} / p} \sum_{s=1}^{s=Q_{s} / p} \tilde{\phi}_{y_{s}}\left(\vartheta_{m}\right)
$$

Hence, the flux density variation in the $s$-th section of the stator yoke can be computed as

$$
B_{y_{s}}\left(\vartheta_{m}\right)=\frac{\phi_{y_{s}}\left(\vartheta_{m}\right)}{h_{y} L_{s t k}}
$$

where $h_{y}$ is the stator yoke length. Fig. 5 shows the flux density in the stator yoke, as a function of the electrical rotor position $\vartheta_{m}^{e}$. It is noted that there is a good agreement between the analytical and the FE analyses results.

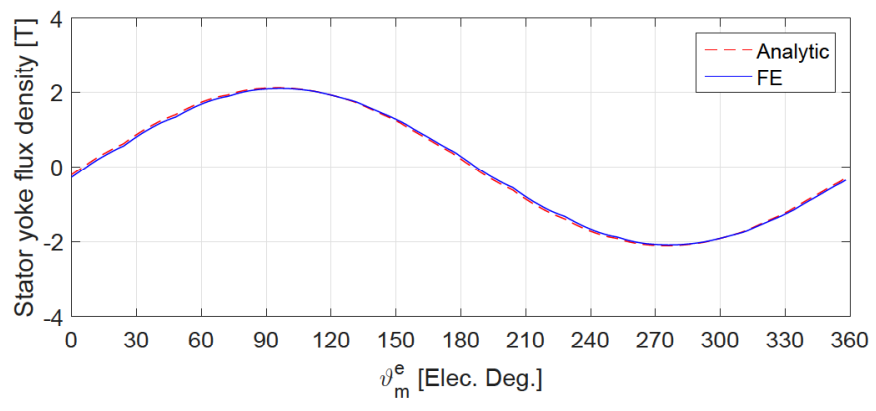

Fig. 5: Flux density in the stator yoke versus rotor position computed from the analytical and FE models at the operating point B.

\section{B. Rotor iron parts}

Fig. 6 (a) shows the different flux paths in a rotor pole. The fluxes entering, going out, and flowing through the $i-$ th rotor island (i.e., $\phi_{i n_{i}}, \phi_{\text {out }_{i}}$, and $\phi_{i s_{i}}$ ) are highlighted. It is assumed that $\phi_{i s_{i}}$ is constant through the island and equal to 
the flux flowing in the middle of the island itself. Fig. 6 (b) presents the equivalent magnetic network of the $i$-th island considering the aforementioned assumption.

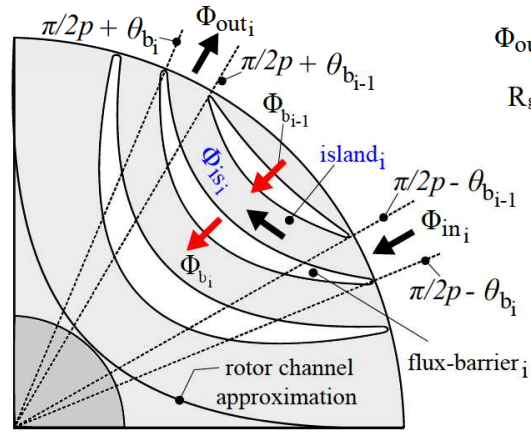

(a)

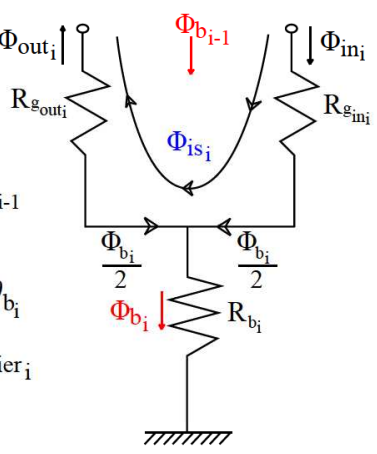

(b)
Fig. 6: The computation of the magnetic flux flowing through the $i$-th rotor island is explained by (a) cross section of the rotor pole and (b) a simple magnetic network.

From Fig. 6, $\phi_{i s_{i}}\left(\vartheta_{m}\right)$ is computed as

$$
\phi_{i s_{i}}\left(\vartheta_{m}\right)=\phi_{i n_{i}}\left(\vartheta_{m}\right)-\frac{\phi_{b_{i}}\left(\vartheta_{m}\right)+\phi_{b_{i-1}}\left(\vartheta_{m}\right)}{2}
$$

where $\phi_{b_{i}}\left(\vartheta_{m}\right)$ is given by

$$
\phi_{b_{i}}\left(\vartheta_{m}\right)=\phi_{i n_{i}}\left(\vartheta_{m}\right)-\phi_{\text {out }_{i}}\left(\vartheta_{m}\right)
$$

By integrating the air-gap flux density, $\phi_{i n_{i}}\left(\vartheta_{m}\right)$ and $\phi_{\text {out }_{i}}\left(\vartheta_{m}\right)$ are computed as

$$
\begin{aligned}
& \phi_{\text {in }_{i}}\left(\vartheta_{m}\right)=\int_{\frac{\pi}{2 p}-\vartheta_{b_{i}}}^{\frac{\pi}{2 p}-\vartheta_{b_{i-1}}} B_{g}\left(\vartheta_{s}, \vartheta_{m}\right) \frac{D L_{s t k}}{2} \mathrm{~d} \vartheta_{\mathrm{s}} \\
& \phi_{\text {out }_{i}}\left(\vartheta_{m}\right)=\int_{\frac{\pi}{2 p}+\vartheta_{b_{i-1}}}^{\frac{\pi}{2 p}+\vartheta_{b_{i}}} B_{g}\left(\vartheta_{s}, \vartheta_{m}\right) \frac{D L_{s t k}}{2} \mathrm{~d} \vartheta_{\mathrm{s}}
\end{aligned}
$$

Finally, the flux density of the $i-$ th island is computed as

$$
B_{i s_{i}}\left(\vartheta_{m}\right)=\frac{\phi_{i s_{i}}\left(\vartheta_{m}\right)}{w_{r_{i}} L_{s t k}}
$$

where $w_{r_{i}}$ is the width of the $i$-th iron path, computed as illustrated in [17]. Fig. 7 shows the flux density variation in the first, second, and third rotor island, and rotor channel, respectively. The results are shown only for 60 electrical degrees since they are repeated six times per one electric period. It is noted that there is a satisfactory agreement between the analytical and FE models.

\section{IRON LOSSES COMPUTATIONS}

The iron losses of a generic motor lamination consist of the sum of hysteresis (hy) and eddy currents (ec) losses. Both of them can be estimated through Steinmetz formula as follows

$$
p_{F e}=p_{h y}+p_{e c}=k_{h y} B^{\beta} f+k_{e c} B^{2} f^{2} \quad[\mathrm{~W} / \mathrm{kg}]
$$

where $k_{h y}$ and $k_{e c}$ are the hysteresis and eddy current constants respectively. They are computed from the data sheet of the lamination by implementing the curve fitting. $\beta$ is

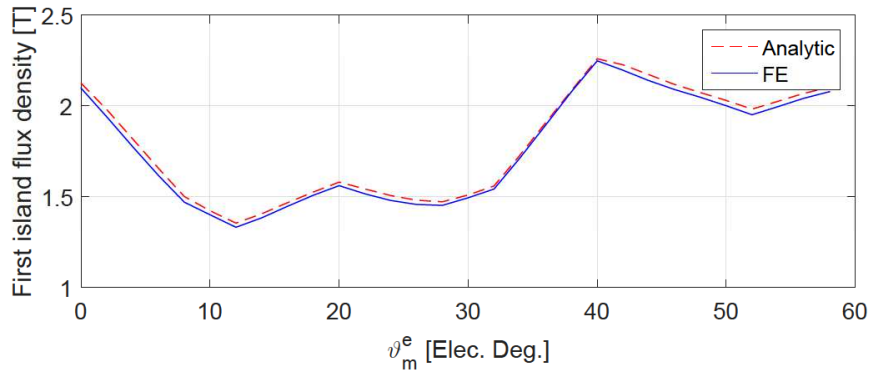

(a) First island

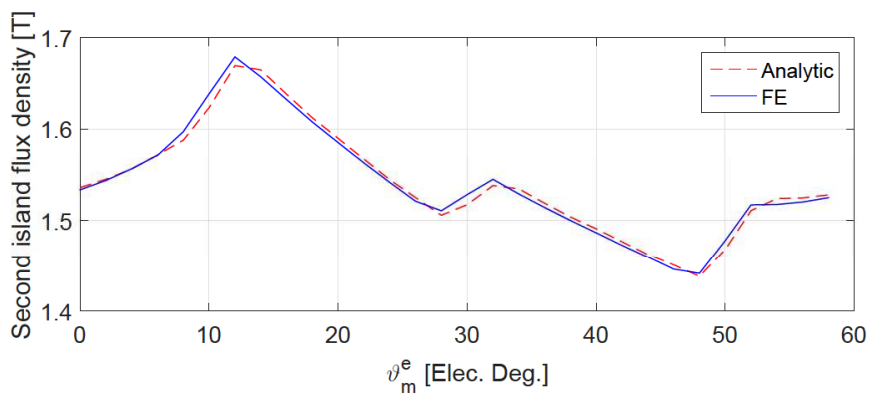

(b) Second island

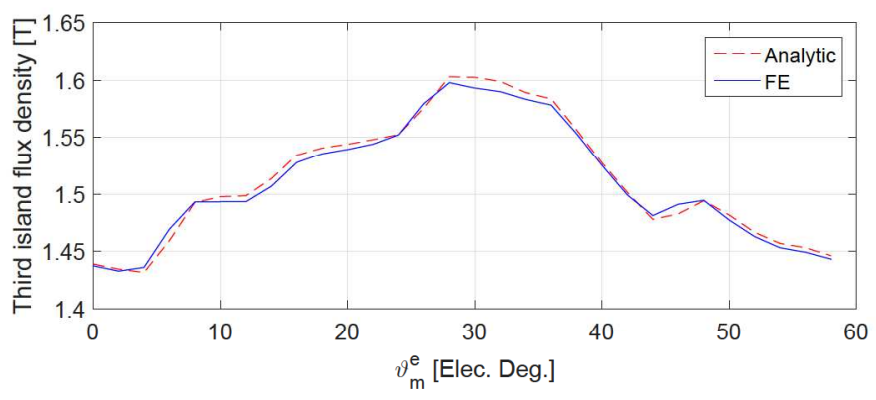

(c) Third island

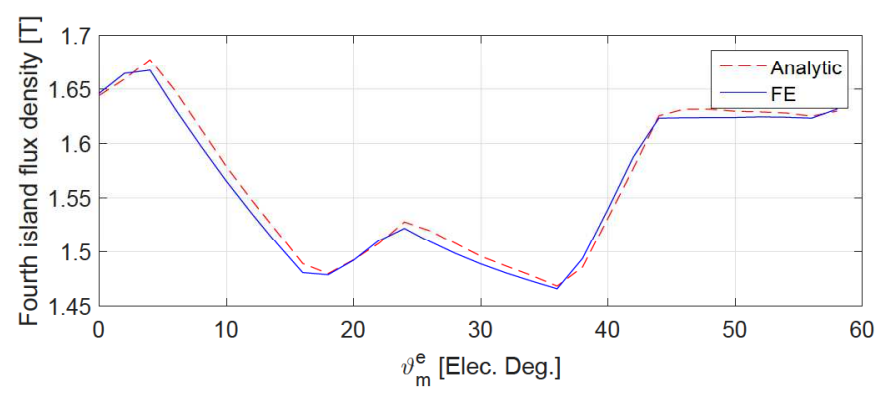

(d) Channel

Fig. 7: Flux density variations in the iron parts of the first rotor pole resulting from the analytical and FE models at the operating point $\mathrm{B}$.

the Steinmetz constant, often approximated to 2, as reported in [15].

In the following, hysteresis losses are considered just for the fundamental (in the stator teeth and the yoke) while eddy current losses are computed for both the first harmonic and all the others. All the harmonics cause losses which are proportional to the time-variation of the flux density inside the different parts of the motor iron. Considering a constant rotor 
speed $\omega_{m}$, it is possible to link the rotor position $\vartheta_{m}^{e}$ to the variation with time $t$, by means of the relation $\vartheta_{m}^{e}=\omega_{m}^{e} t$. In particular, they are

$$
p_{e c}=\frac{\tilde{k}_{e c}}{T} \int_{0}^{T}\left(\frac{\partial B}{\partial t}\right)^{2} d t=\frac{\tilde{k}_{e c}}{2 \pi} \int_{0}^{2 \pi}(\frac{\partial B}{\partial \vartheta_{m}^{e}} \underbrace{\frac{\mathrm{d} \vartheta_{m}^{e}}{\mathrm{~d} t}}_{\omega_{m}^{e}})^{2} \mathrm{~d} \vartheta_{m}^{e}
$$

Once the generic flux density $B$ is split in its Fourier series, as follows

$$
B\left(\vartheta_{m}^{e}\right)=\sum_{h} B_{h} \sin \left(h \vartheta_{m}^{e}+\gamma_{h}\right)
$$

its variation with the rotor position can be easily computed as

$$
\frac{\partial B}{\partial \vartheta_{m}^{e}}=\sum_{h} B_{h} h \cos \left(h \vartheta_{m}^{\epsilon}+\gamma_{h}\right)
$$

and finally

$$
p_{\mathrm{ec}}=k_{\mathrm{ec}} f^{2} \sum_{h} B_{h}^{2} h^{2}
$$

where $\tilde{k}_{\mathrm{ec}}=k_{\mathrm{ec}} / 2 \pi^{2}$, and $f$ is the frequency related to the rotor speed, $n_{s}$, by

$$
f=\frac{p n_{s}}{60}
$$

From (19), it can be noted the remarkable impact of both the speed of the motor and the harmonic order on the eddy current losses. Lastly, dropping the summation symbol, the losses individually associated to each harmonic can be obtained.

A silicon iron lamination, with specific iron losses equal to $1.5 \mathrm{~W} / \mathrm{kg}$ at $1 \mathrm{~T}$ and $50 \mathrm{~Hz}$, is considered. In these conditions the eddy current and the hysteresis losses account for $30 \%$ and $70 \%$, respectively. Hence, $k_{e c}=0.18 \cdot 10^{-3} \mathrm{~W} /\left(\mathrm{kg} \mathrm{T}^{2} \mathrm{~Hz}^{2}\right)$ and $k_{h y}=0.021 \mathrm{~W} /\left(\mathrm{kg} \mathrm{T}^{2} \mathrm{~Hz}\right)$ are obtained.

Considering the operating point B, Table I reports the eddy current and hysteresis losses which occur in stator teeth and yoke, respectively. In addition, Table II shows the eddy current losses which occur in the different iron parts of a rotor pole. Again, there is a good agreement between the analytical model and the FE analysis: from Table I, the error is lower than $2 \%$.

Then, the analytical model is adopted to predict the losses at the operating point B'. The same agreement with the FE analysis is noted as shown in Tables III and IV. Since the current angle is increased up to $80^{\circ}$, the main flux in the machine is reduced. Thus, the iron losses due to the fundamental flux component are reduced, as noted in Table III. On the contrary, the contribution of the flux harmonics to the iron losses increases, as highlighted in Table III. This is due to the higher machine speed (thus frequency) and the higher harmonic content in the flux density variations in iron parts. It can be concluded that for the stator teeth, the eddy current losses at the operating point B' are higher than those at point B and vice versa for the hysteresis losses. The iron losses in the stator yoke are reduced due to the reduction of the fundamental component.

From Tables II and IV, it is noted that the eddy current losses increase in the rotor too. However, these losses are quite
TABLE I: Eddy current and hysteresis loss densities in the stator teeth and yoke at the operating point $\mathrm{B}$.

\begin{tabular}{lllll}
\hline Iron part & \multicolumn{2}{c}{ Analytical } & \multicolumn{2}{c}{ FE } \\
& $h=1$ & $h>1$ & $h=1$ & $h>1$ \\
\hline \multicolumn{5}{r}{ Eddy current loss density $[\mathrm{W} / \mathrm{kg}]$} \\
\hline Yoke & 15.2 & 0.4 & 14.9 & 0.46 \\
First tooth & 8.3 & 3.3 & 8.1 & 3.1 \\
Second tooth & 8.6 & 3.5 & 8.4 & 3.4 \\
Third tooth & 10.7 & 2.9 & 10.6 & 2.8 \\
\hline \multicolumn{5}{c}{ Hysteresis loss density $[\mathrm{W} / \mathrm{kg}]$} \\
\hline Yoke & 17.7 & - & 17.4 & - \\
First tooth & 9.7 & - & 9.5 & - \\
Second tooth & 10 & - & 9.84 & - \\
Third tooth & 12.5 & - & 12.3 & - \\
\hline \multicolumn{5}{c}{ Stator loss density [W/kg] } \\
\hline \multicolumn{5}{c}{ Analytical } \\
\hline Stator tooth & \multicolumn{5}{c}{ FE } \\
Stator yoke & 33.2 \\
\hline Model error & \multicolumn{3}{c}{32.7} \\
\hline
\end{tabular}

TABLE II: Eddy current loss densities in the rotor islands and channel at the operating point $\mathrm{B}$.

\begin{tabular}{lll}
\hline Iron part & Analytical $[\mathrm{W} / \mathrm{kg}]$ & $\mathrm{FE}[\mathrm{W} / \mathrm{kg}]$ \\
\hline island 1 & 27.35 & 28.32 \\
island 2 & 1.303 & 1.37 \\
island 3 & 0.81 & 0.72 \\
channel & 1.55 & 1.45 \\
\hline
\end{tabular}

TABLE III: Eddy current and hysteresis loss densities in the stator teeth and yoke at the operating point B'.

\begin{tabular}{lcccc}
\hline Iron part & \multicolumn{2}{c}{ Analytical } & \multicolumn{2}{c}{ FE } \\
& $h=1$ & $h>1$ & $h=1$ & $h>1$ \\
\hline \multicolumn{4}{c}{ Eddy current loss density [W/kg] } \\
\hline Yoke & 4.20 & 1.94 & 3.90 & 1.96 \\
First tooth & 1.86 & 20.9 & 1.83 & 20.5 \\
Second tooth & 2.30 & 20.7 & 2.25 & 21.1 \\
Third tooth & 4.33 & 18.5 & 3.90 & 17.9 \\
\hline \multicolumn{5}{c}{ Hysteresis loss density $[\mathrm{W} / \mathrm{kg}]$} \\
\hline Yoke & 2.45 & - & 2.27 & - \\
First tooth & 1.09 & - & 1.07 & - \\
Second tooth & 1.34 & - & 1.31 & - \\
Third tooth & 2.53 & - & 2.27 & - \\
\hline \multicolumn{5}{c}{ Stator loss density [W/kg] } \\
\hline \multicolumn{5}{c}{ Analytical } \\
\hline Stator tooth & 24.5 \\
Stator yoke & 8.59 \\
\hline Model error & \multicolumn{5}{c}{24} \\
\hline
\end{tabular}

low with respect to the stator losses and can be neglected if the rotor is laminated, as in this case of study.

\section{OPTIMIZATION APPROACH}

Thanks to the fast and accurate analytical model presented in the previous sections, an optimization of the machine has been tailored in order to explore the possible solutions that can be carried out over a greater number of samples in a very short time with respect to any FE tool. The precise calculation of average torque and torque ripple has been addressed and 
TABLE IV: Eddy current loss densities in the rotor islands and channel at the operating point B'.

\begin{tabular}{lll}
\hline Iron part & Analytical $[\mathrm{W} / \mathrm{kg}]$ & $\mathrm{FE}[\mathrm{W} / \mathrm{kg}]$ \\
\hline island 1 & 51.5 & 42.8 \\
island 2 & 9.77 & 9.98 \\
island 3 & 2.61 & 2.37 \\
channel & 8.94 & 8.43 \\
\hline
\end{tabular}

TABLE V: Input variables range properties.

\begin{tabular}{|c|c|c|c|c|}
\hline \multirow[t]{2}{*}{ Name } & \multirow{2}{*}{ Symbol } & \multicolumn{2}{|c|}{ Boundaries } & \multirow[t]{2}{*}{ Unit } \\
\hline & & Lower & Upper & \\
\hline Flux barrier angle 1 & $\theta_{b 1}$ & 10 & 20 & degrees \\
\hline Flux barrier angle 2 & $\theta_{b 2}$ & 21 & 32 & degrees \\
\hline Flux barrier angle 3 & $\theta_{b 3}$ & 33 & 40 & degrees \\
\hline Insulation coefficient & $k_{a i r}$ & 0.28 & 0.55 & - \\
\hline
\end{tabular}

validated in [15] through FE. In this paper, the iron losses computation is adding value to the optimization process of the machine. This highlights the effect of different parameters and segregate their impact with respect to the machine geometry. To the aim of simplifying the problem and understanding the effect of the complex rotor geometry on the iron losses, only four rotor parameters have been selected:

- the three flux barriers end angles $\theta_{b 1}, \theta_{b 2}, \theta_{b 3}$;

- the air coefficient $k_{a i r}$.

Table V reports a summary of the input variables and their limits set for the optimization. The stator geometry, air-gap, stack length and the electric loading are kept constant. In 「18], an optimization has been carried out for two different operating points, where the motor is working most frequently, to the aim of considering actual operating conditions.

A similar procedure has been applied in this work. Always referring to the motor geometry used for the flux density calculations, an optimization algorithm has been performed to minimize torque ripple ( $\left.\tau_{\text {ripple }}\right)$, yoke losses $\left(p_{y}\right)$ and teeth losses $\left(p_{t}\right)$, as reported in (20a), (20b) and (20c), while monitoring and maximizing the average torque $\left(\tau_{a v g}\right)$ as in (20d). With the target of optimizing all the objective functions at both rated (point B) and higher speed (point B'), before the MTPV control strategy is applied, the selected targets are summarized as follows:

$$
\left\{\begin{array}{l}
\min \left(\tau_{\text {ripple }_{B}}\right), \min \left(\tau_{\text {ripple }_{B^{\prime}}}\right) \\
\min \left(p_{y_{B}}\right), \min \left(p_{y_{B^{\prime}}}\right) \\
\min \left(p_{t_{B}}\right), \min \left(p_{t_{B^{\prime}}}\right) \\
\max \left(\tau_{m_{B}}\right), \max \left(\tau_{m_{B^{\prime}}}\right) \\
\min \left(\Delta \tau_{m}\right)=\min \left|\tau_{m_{B}}-\tau_{m_{B^{\prime}}}\right| \\
\min \left(\Delta \tau_{\text {ripple }}\right)=\min \left|\tau_{\text {ripple }_{B}}-\tau_{\text {ripple }_{B^{\prime}}}\right| \\
\min \left(\Delta p_{y}\right)=\min \left|p_{y_{B}}-p_{y_{B^{\prime}}}\right| \\
\min \left(\Delta p_{t}\right)=\min \left|p_{t_{B}}-p_{t_{B^{\prime}}}\right|
\end{array}\right.
$$

The last four equations (20e) - (20h), have been defined to the aim of directing the algorithm to converge to similar values of torque and loss for both working conditions B and B'. In other words, these additional objectives would minimize the difference between the performance in B and B'.

\section{A. Optimization results}

The optimization has been performed using the analytical model combined with the software ModeFRONTIER by ESTECO. The optimization algorithm NSGA-II has been chosen to achieve a fast Pareto convergence. It has been applied to a number of 150 individuals per population, with 60 following generations for a total number of 9000 evaluations. This required about four hours using Pentium 4. 3.5-GHz computer, 360 steps for a whole turn. Using the same strategy with a FE based analysis, it would have taken a computational time of some days.

In this section, some optimization results are reported showing the correlation among the different output variables. The analysis of these plots are useful to evaluate qualitatively the amplitude and variation range of the target output functions, as well as to determine the best solution.

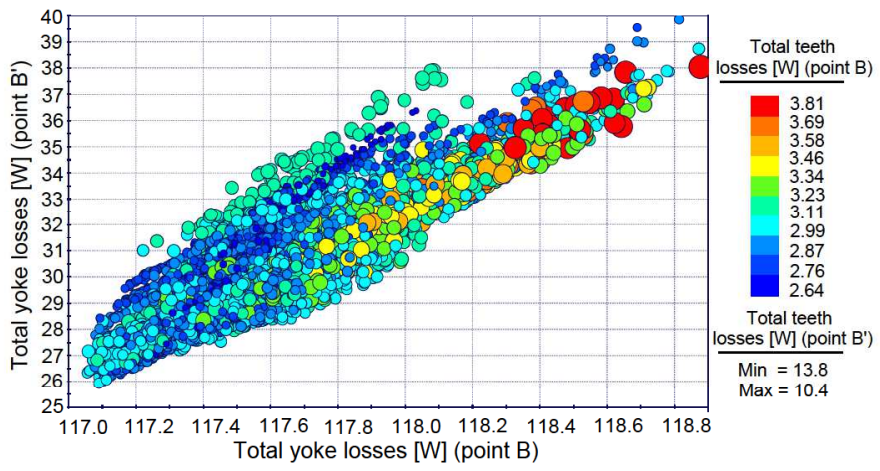

Fig. 8: Iron losses behaviour in the yoke and correlation with the tooth for both operating points (B and B').

Fig. 8 shows a representative plot of the optimization results in four different dimensions. The solutions converge to lower yoke losses at both rated (point B) and (point B'), higher operating speed, reported respectively on horizontal and vertical axes. The colour gradient and the bubbles diameter, on the right hand side legend, highlight the tooth iron losses in point B and B', respectively. For example, it is clear that if at rated speed, there is a limited influence on the yoke losses (less than $1 \%$ ), while at point B' the variation is higher than $40 \%$.

The torque ripple follows the same converging trend, as reported in Fig. 9. As far as the average torque is concerned, it is not affected considerably because of the optimization of the only rotor geometry. It ranges between 7 to $7.5 \mathrm{Nm}$. On the contrary, the torque oscillations are more sensitive to the rotor parameters, showing variations between 8 to 38 percent at the base speed and significantly higher in point B'.

Figs. 10 and 11 show the relation between the iron losses in the teeth and yoke with respect to the torque ripple in the two operating points. In both graphs, the colour gradient and bubble diameter of the solutions represent the torque ripple 


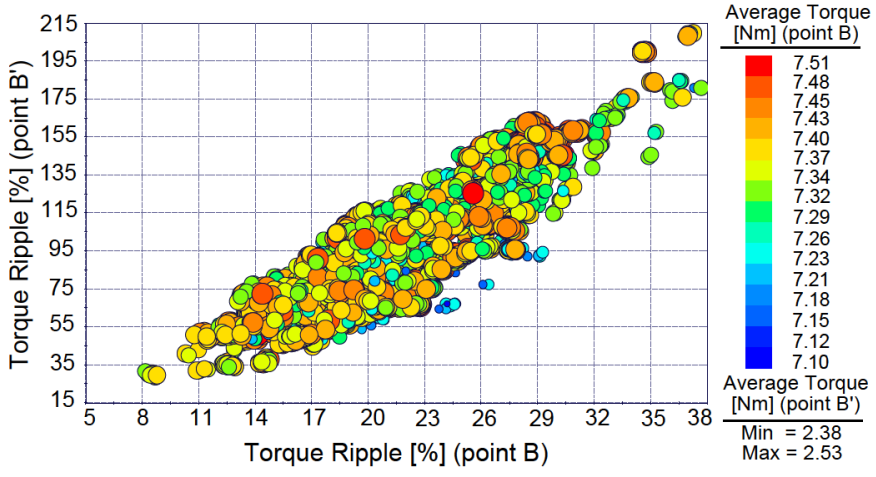

Fig. 9: Behaviour of torque ripple and correlation with the average torque for both operating point (B and B').

percentage with the same scales. The convergence trend with respect to the latter is opposite. The higher the torque ripple, the lower the teeth iron losses. With respect to the yoke, the lower the losses the lower the ripple. This confirms the strong correlation of the torque oscillations and teeth losses.

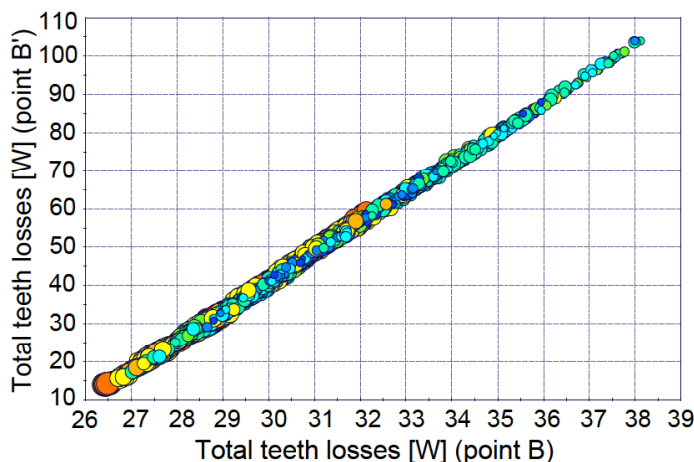

Torque ripple [\%] (point B)
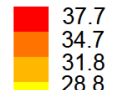

Total teeth losses [W] (point B)

$\operatorname{Max}=210$

Fig. 10: Behaviour of teeth iron losses versus the torque ripple for both operating point (B and B').

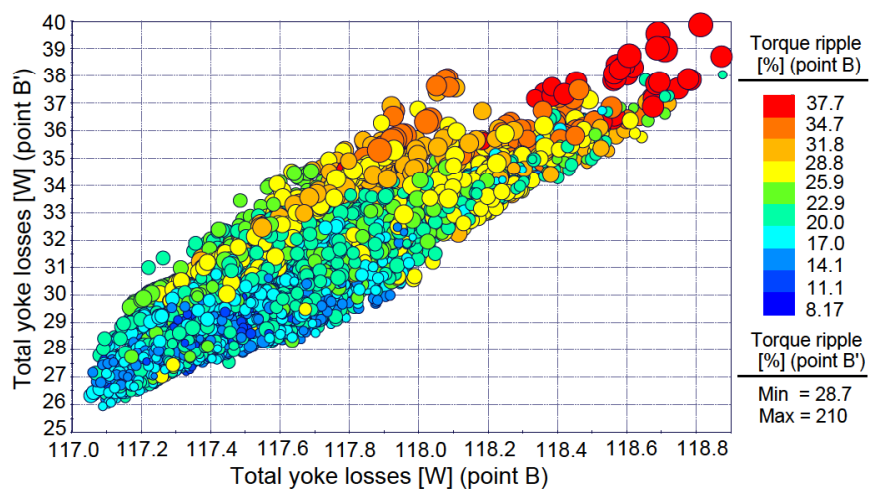

Fig. 11: Behaviour of yoke iron losses versus the torque ripple for both operating point (B and B').

The best solutions can be identified as a compromise between the correlations highlighted in the previous part. To simplify the interpretation of the optimization results and translate those in more practical solutions, Table VI summarizes the input variables range giving the optimal motor geometries together with the quantitative output variables.

TABLE VI: Optimal variables range.

\begin{tabular}{lllll}
\hline Name & Symbol & \multicolumn{2}{c}{ Boundaries } & Unit \\
& & Lower & Upper & \\
\hline Flux barrier angle 1 & $\theta_{b 1}$ & 14.4 & 15.5 & degrees \\
Flux barrier angle 2 & $\theta_{b 2}$ & 30.5 & 31.6 & degrees \\
Flux barrier angle 3 & $\theta_{b 3}$ & 36.5 & 37.5 & degrees \\
Insulation coefficient & $k_{\text {air }}$ & 0.38 & 0.4 & - \\
\hline Parameter & Symbol & Operating point & Unit \\
& & B & B' & \\
Yoke losses & $p_{y}$ & $<117.5$ & $<30$ & $W$ \\
Teeth losses & $p_{t}$ & $<35$ & $<50$ & $W$ \\
Torque ripple & $\tau_{\text {ripple }}$ & $\approx 8$ & $<20$ & $\%$ \\
\hline
\end{tabular}

\section{CONCLUSIONS}

This paper describes the analytical computations of the flux density variations in the different iron parts of the SynRel motor. These parts are the rotor islands and the stator yoke and teeth. The eddy current losses are computed considering all the harmonic contributions while the hysteresis losses are computed for the fundamental component only, neglecting the minor hysteresis loops. There is a good agreement between the analytical model and FE analysis results.

Thanks to the computational speed and good accuracy of the analytical model, the rotor geometry has been optimized with the objective of minimizing the torque ripple and the iron losses in both stator teeth and yoke, as well as, maximizing the average torque. The approach has been applied into an optimization procedure to design the motor at two different operating points, B and B' simultaneously. The results allow to understand the correlation between the sources of losses and torque ripple, not only for one operating point as conventionally considered. This approach has been used to find those solutions that are more stable to the variation of operating conditions.

\section{REFERENCES}

[1] A. Krings and J. Soulard, "Overview and comparison of iron loss models for electrical machines," in 5th International Conference and Exhibition on Ecological Vehicles and Renewable Energies (EVER 10), MonteCarlo, Monaco, March 25-28, 2010.

[2] M. Masoudinejad, S. Feldhorst, F. Javadian, and M. Hompel, "Reduction of energy consumption by proper speed selection in PMSM-driven roller conveyors," in IEEE Transactions on Industry Applications, vol. 51, no. 2, pp. 1572-1578, March 2015.

[3] J. Estima and A. J. M. Cardoso, "Efficiency analysis of synchronous reluctance motors," in International Conference of EngineeringICEUBI, Covilha, Portugal, 27-29 Nov. 2013.

[4] A. Krings, M. Cossale, J. Soulard, A. Boglietti, and A. Cavagnino, "Manufacturing influence on the magnetic properties and iron losses in cobalt-iron stator cores for electrical machines," in IEEE Energy Conversion Congress and Exposition (ECCE), Pittsburgh, PA, USA, Sept 2014, pp. 5595-5601.

[5] M. Barcaro and N. Bianchi, "Air-gap flux density distortion and iron losses in anisotropic synchronous motors," in IEEE Transactions on Magnetics, vol. 46, no. 1, pp. 121-126, Jan 2010. 
[6] F. Leonardi, T. Matsuo, and T. A. Lipo, "Iron loss calculation for synchronous reluctance machines," in Proceedings of the 1996 International Conference on Power Electronics, Drives and Energy Systems for Industrial Growth, vol. 1, Jan, pp. 307-312.

[7] F. Magnussen, Y. K. Chin, J. Soulard, A. Broddefalk, S. Eriksson, and C. Sadarangani, "Iron losses in salient permanent magnet machines at field-weakening operation," in Conference Record of the 39th IAS Annual Meeting of IEEE Industry Applications., vol. 1, Oct 2004, pp. 40-47.

[8] W. Roshen, "Iron loss model for permanent-magnet synchronous motors," in IEEE Transactions on Magnetics, vol. 43, no. 8, pp. 3428-3434, Aug 2007.

[9] B. Stumberger, A. Hamler, and B. Hribernik, "Analysis of iron loss in interior permanent magnet synchronous motor over a wide-speed range of constant output power operation," in IEEE Transactions on Magnetics, vol. 36, no. 4, pp. 1846-1849, Jul 2000.

[10] K. Yamazaki and Y. Seto, "Iron loss analysis of interior permanentmagnet synchronous motors-variation of main loss factors due to driving condition," in IEEE Transactions on Industry Applications, vol. 42, no. 4, pp. 1045-1052, July 2006.

[11] S. H. Han, W. L. Soong, and T. M. Jahns, "An analytical design approach for reducing stator iron losses in interior PM synchronous machines during flux-weakening operation," in Conference Record of the 42nd IAS Annual Meeting of IEEE Industry Applications, Sept 2007, pp. 103-110.

[12] G. Pellegrino, P. Guglielmi, A. Vagati, and F. Villata, "Core losses and torque ripple in IPM machines: Dedicated modeling and design tradeoff," IEEE Transactions on Industry Applications, vol. 16, no. 6 , pp. 2381-2391, Nov 2010.

[13] H. Mahmoud, M. Degano, G. Bacco, N. Bianchi, and C. Gerada, "Synchronous reluctance motor iron losses: Part II- considering the machine non-linearity at MTPA and FW operating conditions," in IEEE Transactions on Energy Conversion, in press.

[14] M. Degano, E. Carraro, and N. Bianchi, "Robust optinnization of a traction PMASR motor according to given driving cycles," International Conference on Electrical Machines (ICEM), Berlin, Germany, pp. 270276, Sept 2014.

[15] M. Degano, H. Mahmoud, N. Bianchi, and C. Gerada, "Synchronous reluctance machine analytical model optimization and validation through finite element analysis," In 22-th International Conference on Electrical Machines (ICEM), Lausanne, Switzerland, pp. 585-591, Sept 2016.

[16] H. Mahmoud and N. Bianchi, "Eccentricity in synchronous reluctance motors; Part I: Analytical and finite-element models," in IEEE Transactions on Energy Conversion, vol. 30, no. 2, pp. 745-753, June 2015.

[17] N. Bianchi, H. Mahmoud, and S. Bolognani, "Fast synthesis of permanent magnet assisted synchronous reluctance motors," in IET Electric Power Applications, vol. 10, no. 5, pp. 312-318, 2016.

[18] M. Degano, E. Carraro, and N. Bianchi, "Selection criteria and robust optimization of a traction PM-assisted synchronous reluctance motor,' IEEE Transactions on Industry Applications, vol. 51, no. 6, pp. 43834391, Nov 2015. 